\title{
Phytotoxicity of colloidal solutions of stabilized and non-stabilized nanoparticles of essential metals and their oxides
}

\author{
Yevheniia Konotop $^{\bowtie}$, Kseniia Stepanchenko, Leila-Anastasiia Karpets, Andrii Zinchenko, \\ Mariia Kovalenko, Oleksandr Smirnov, Ludmila Batsmanova and Nataliya Taran
}

Educational and Scientific Center, Institute of Biology and Medicine, Taras Shevchenko National University of Kyiv, 64/13 Volodymyrska str., Kyiv, 01601,Ukraine

Article info

\section{Article history:}

Received: $18^{\text {th }}$ January 2019

Accepted: $14^{\text {th }}$ April 2019

\section{Keywords:}

Allium cepa (L.)

Root meristem

Mitosis

Chromosomal aberrations

Metal nanoparticles

Stabilized nanoparticles

Phytotoxicity

\begin{abstract}
Advances in nanotechnology in various fields of human activity contribute to increase of their production, improved properties and wider implementation of nanomaterials. However, increasing use may enhance their release into the environment and can lead to affecting human health. The toxicity of colloidal solutions of metal nanoparticles $(\mathrm{Cu}, \mathrm{Mn})$ and their oxides, obtained in the absence and presence of a stabilizer, was examined and compared with the use of the standard test system of Allium cepa L.. The phytotoxicity of the experimental solutions was evaluated according to the growth response of the onion roots; the cyto- and genotoxicity were estimated due to the proliferative activity of the root meristem cells. It was established that solutions of stabilized metal nanoparticles were at given concentration toxic to Allium cepa $\mathrm{L}$. according to the integral index of roots growth, however, were not cytotoxic. Difference in the phytotoxicity of stabilized and non-stabilized metal nanoparticles and their oxides depended on their phase composition and affected root growth.
\end{abstract}

\section{Introduction}

Advances of nanotechnology in various fields of human activity contributed to increased production and wider implementation of nanomaterials (Scrinis and Lyons 2007; Rui et al. 2016; Ditta and Arshad 2016; Ruttkay-Nedecky et al. 2017). Recent evidence suggests the efficiency of metal nanoparticles (NPs) and their oxides in reducing the toxic effects of adverse stressors on crops through the activation of their protective systems, which is a good prerequisite for wider use of nanomaterials in the agriculture as fertilizers or plant protection factors (Abdel Latef et al. 2016; Saxena et al. 2016; Taran et al. 2016; Konate et al. 2017). However, increased use of nanomaterials may enhance their release into the environment as well (e.g. during their synthesis, incorporation into goods, reaching wastewaters and soil etc.) and affect human health. Plants, as components of ecosystems, play a significant role in accumulation and circulation of nano-sized products in nutrition chains. The potential impact of NPs on plants, however, requires thorough study, since available data on their toxicity (in comparison to ionic forms or bulk material) are highly controversial (Griffitt et al. 2008; Ma et al. 2013; Konotop et al. 2014; Liu et al. 2016). The direct toxicity of metal NPs and their oxides depends on the chemical composition of the raw material (for example, due to the release of toxic ions), the physical 
Table 1. Characteristics of experimental colloidal solutions of nanoparticles of essential metals obtained by using the X-ray crystallography.

\begin{tabular}{|c|c|c|c|c|c|c|}
\hline \multirow[b]{2}{*}{ Sample } & \multirow{2}{*}{$\begin{array}{c}\text { Size } \\
{[\mathbf{n m}]}\end{array}$} & \multicolumn{2}{|c|}{ Phase content } & \multicolumn{3}{|c|}{ Lattice parameter [nm] } \\
\hline & & Phase & $\begin{array}{c}\text { Mass portion } \\
{[\%]}\end{array}$ & $\mathbf{a}$ & b & c \\
\hline Trisodium citrate & - & Trisodium citrate & 100.00 & 12.817 & 5.625 & 11.484 \\
\hline \multirow{2}{*}{ Non-stabilized Mn } & 53 & Mn & 97.84 & 4.793 & 4.793 & 15.627 \\
\hline & 64 & $\mathrm{MnO}$ & 2.16 & 4.440 & 4.440 & 14.453 \\
\hline \multirow{2}{*}{ Non-stabilized $\mathrm{Cu}$} & 78 & $\mathrm{Cu}$ & 91.55 & 4.266 & 4.266 & 12.393 \\
\hline & 82 & $\mathrm{Cu}_{2} \mathrm{O}$ & 8.45 & 3.617 & 3.617 & 10.724 \\
\hline \multirow{2}{*}{ Stabilized Mn } & - & Trisodium citrate & 4.24 & 12.807 & 5.521 & 11.477 \\
\hline & 54 & Trisodium citrate-Mn & 94.76 & 5.745 & 5.745 & 12.836 \\
\hline \multirow{2}{*}{ Stabilized $\mathrm{Cu}$} & - & Trisodium citrate & 6.75 & 12.805 & 5.614 & 11.460 \\
\hline & 75 & Trisodium citrate- $\mathrm{Cu}$ & 93.25 & 6.836 & 6.836 & 11.957 \\
\hline
\end{tabular}

$\mathrm{a}, \mathrm{b}$, and c - lattice parameters in three dimensions. Lattice parameter refers to the physical dimension of unit cells in a crystal lattice

characteristics of NPs (size, shape, surface structure), and/or the ability to generate reactive oxygen species in plant tissues (Navarro et al. 2008; Auffan et al. 2009; Horie et al. 2012; Fu et al. 2014; Tang et al. 2016). In addition, the toxicity of NPs to plants, so called phytotoxicity, which we refer to in this article as the toxicity of NPs to plants, is associated with a disturbance of nutrient uptake by roots owing to alteration of surface composition of the rhizosphere in the presence of NPs (Lee et al. 2012; Mirzajani et al. 2013). Similar effects on test objects were observed for high concentrations of nanoparticles in the nutrient medium (Navarro et al. 2008; Gottschalk et al. 2013). The results of some other studies are ambiguous, since the toxicity of NPs does not always exceed the toxicity of bulk chemical species containing the same elements (Liu et al. 2016), or depends on the metal on the basis of which the colloidal solutions were prepared.

NPs of essential metals, namely of $\mathrm{Cu}$ and $\mathrm{Mn}$, phytotoxicity of which is researched in the present work, have already been widely used in crop production as antimicrobial agents $(\mathrm{Cu}, \mathrm{CuO}$ NPs), or as fertilizers alternative to conventional salts (Mn NPs) (Dimkpa et al. 2011; Liu et al. 2016). It is known that the surface of NPs of many metals possesses elevated chemical activity and instantly interacts with oxygen, water and organic compounds. Therefore, NPs in colloidal solutions require additional stabilization, which depends on the concentration of the metal phase, the chemical composition of the medium, the method of their obtaining, and the presence of complexing ligands. The lack of stabilizing agents could lead to the formation of large aggregates that are gradually oxidized (Sperling and Parak 2010). Among stabilizers for metal NPs are used e.g. ligand-complexing agents (ammonia, ethylene diamine tetraacetic acid, glycerol), surfactants (among others sodium citrate) and polymers (polyethylene glycol, polyvinyl pyrrolidone, polyvinyl alcohol). A common example is gold nanoparticles synthesized in an aqueous solution by reducing citrate (Lin et al. 2004). The resulting NPs adsorb negatively charged citrate ions on their surface and thus are stabilized due to electrostatic repulsion. The presence of stabilizing agents on the surface of NPs provides them new properties, which in turn predetermine the toxicity of nanomaterials (Cunningham et al. 2013; Sharma et al. 2014). So, search for ways to improve the physical and chemical properties of nanomaterials is still in progress, at the same time, careful control of nanoproducts for environment safety with the use of bioassays is also needed (Olkhovych et al. 2016; Teplicky et al. 2018).

Onion, Allium cepa L., belongs to the most common plant species used to assess environmental contamination. It is considered as a short-term, simple in use and sensitive test model, with reliable correlation to other test systems, including human. The macroscopic symptoms of phytotoxicity - 


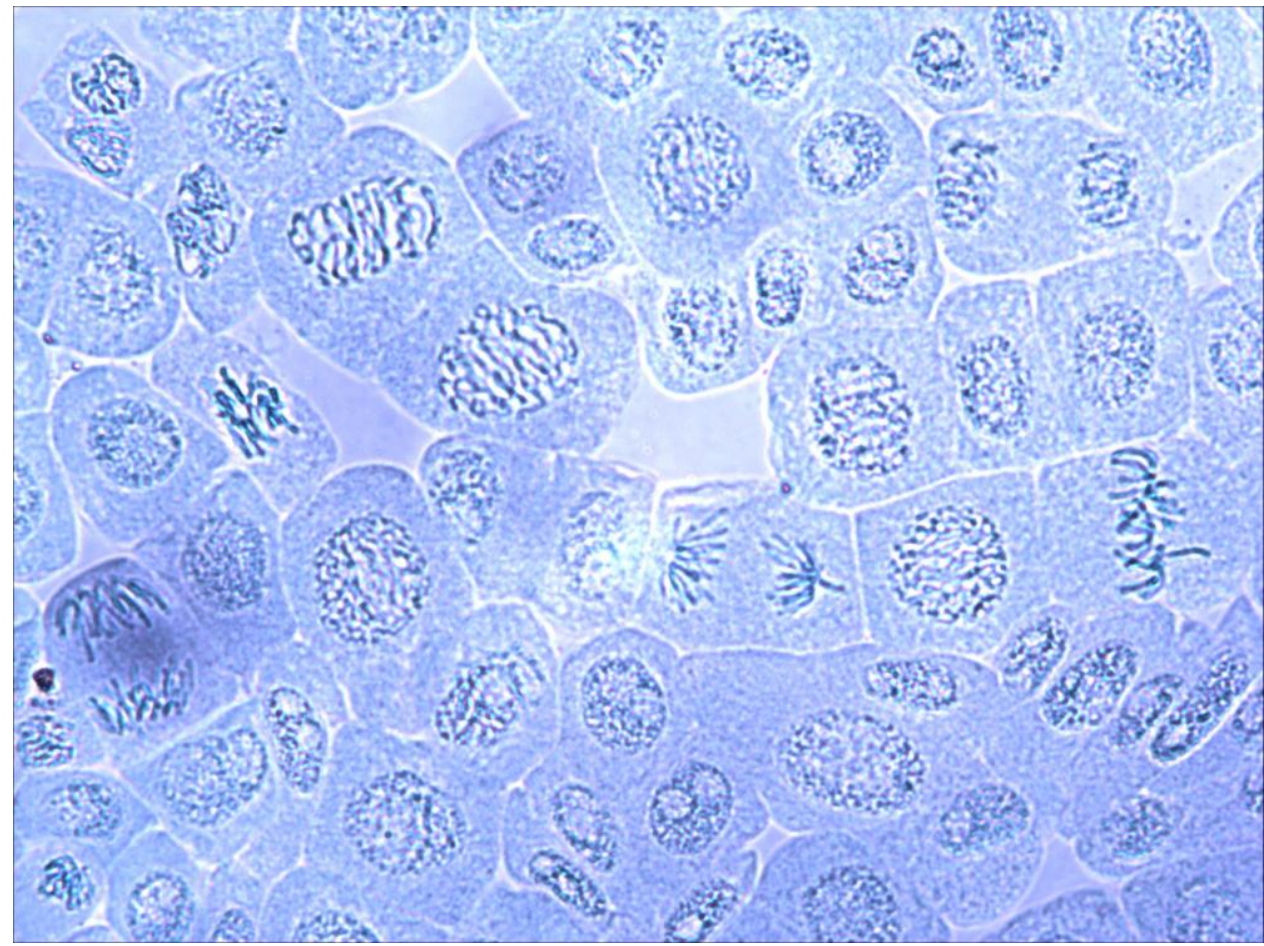

Fig. 1. Root meristem cells of Allium cepa $\mathrm{L}$. in the different phases of mitosis on the $5^{\text {th }}$ day of cultivation (magnification 400x). stunting of root growth, delayed development, or even death of cells/plant, represent the most sensitive test parameters. Microscopic examination allows for assessing proliferative activity of root meristem cells, chromosome damage and cell division disorders, and, therefore, provides additional information on the severity of toxic effect, mechanism of genotoxicity, or potential mutagenicity of tested agents (Fiskesjo 1985).

Therefore, the purpose of this work was to test and compare the phytotoxicity of developed colloidal solutions of essential metals NPs (Mn and $\mathrm{Cu}$ ) and their oxides, obtained in the absence and presence of a stabilizer, using the standard Allium cepa $\mathrm{L}$. test system.

\section{Experimental}

\section{Materials}

Colloidal solutions of stabilized and non-stabilized $\mathrm{Cu}$ and Mn NPs and their oxides were developed and kindly provided by the Department of Technology of Structural Materials and Materials Science, National University of Life and Environmental Sciences of Ukraine, and obtained by dispersing granules of copper and manganese by pulses of electric current with amplitude 100 - $2000 \mathrm{~A}$ in water (Lopatko 2009). Concentrations of $\mathrm{Mn}$ and $\mathrm{Cu}$ NPs in stock solutions were 3 and $4 \mathrm{mg} . \mathrm{L}^{-1}$, respectively. 100-fold diluted solutions were used. Characteristics of the colloidal solutions of NPs are given in the Table 1.

\section{Plant material and growth conditions}

The phytotoxicity of solutions of stabilized and non-stabilized $\mathrm{Cu}$ and Mn NPs were studied using the standard test object Allium cepa L. (Fiskesjo 1985). For each experimental variant 10 equal onion bulbs, cv. Chalcedony, were cultivated on experimental suspensions of NPs for 5 days at $24{ }^{\circ} \mathrm{C}$. Control plants were grown on distilled water. To eliminate the effect of the stabilizer, the plants were additionally cultivated in aqueous solution of trisodium citrate in a concentration that corresponded to that in the experimental solutions of stabilized NPs of essential metals, which is a 100-fold diluted stock solution (2 g.L.-1) of trisodium citrate.

\section{Estimation of growth response}

At the end of the exposure time the fresh weight, length and quantity of roots per bulb were determined. Growth response was estimated 
according to the tolerance index (IT, \%) calculated as the ratio of the fresh weight of roots of experimental group to the same parameter of control group (Wilkins 1978).

\section{Microscopic technique}

Onion roots were fixed in Clark solution (ethanol: acetic acid $=3: 1$ ), macerated in $1 \mathrm{M} \mathrm{HCl}$ at the temperature $45{ }^{\circ} \mathrm{C}$, and stained with $1 \%$ (w/v) aqueous solution of toluidine blue. Temporary oppressed slides with root's tips were prepared and further analyzed under a light microscope (PrimoStar, Carl Zeiss) at 400x magnification.

\section{Cyto- and genotoxicity estimation}

Different phases of mitosis in cells of the root apical meristem were counted to calculate mitotic/phase indices, and mitosis abnormalities (Fig. 1). Presence of micronuclei was observed for evaluation of cyto- and genotoxic effects of the experimental solutions (Fiskesjo 1997).

The mitotic index (MI, \%) was presented as number of cells in the state of division to the total number of observed cells (3000) (Eq.1):

$$
\mathrm{MI}=\frac{(P+M+A+T)}{(I+P+M+A+T)} \times 100 \%,
$$

where P, M, A, T, I are quantities of cells in pro-, meta-, ana-, telo-, and interphase of mitosis, respectively.

Phase indices (\%) were calculated as number of cells on certain mitosis phase $(\mathrm{P}, \mathrm{M}, \mathrm{A}, \mathrm{T})$ to the total number of divided cells. For example, prophase index (PI, \%) (Eq. 2):

$$
\mathrm{PI}=\frac{P}{(P+M+A+T)} \times 100 \%
$$

\section{Statistical analysis}

Each experiment was performed at least in triplicate. The data were subjected to analysis of variance (ANOVA) with subsequent Student's t-test or Duncan's multiple range test.

Data are expressed as means of replicates \pm standard deviation, and were considered as significant at $P<0.05$.

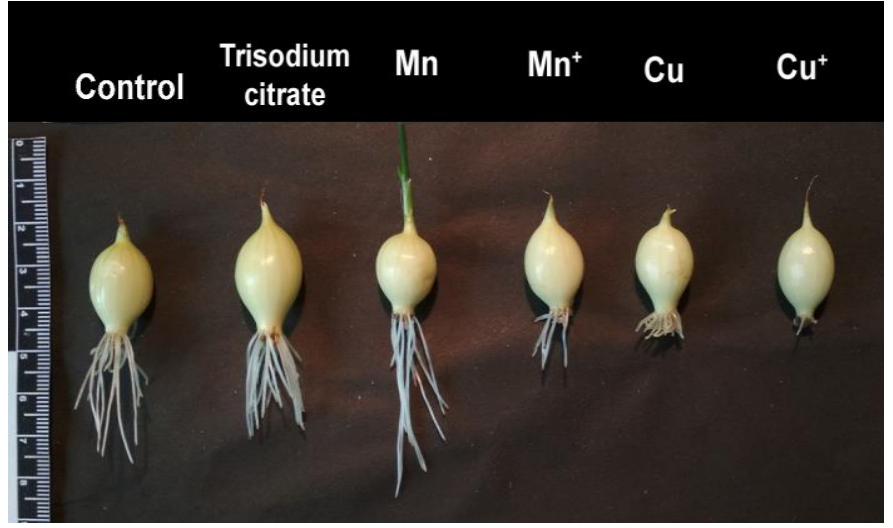

Fig. 2. Growth response of Allium cepa L. on $5^{\text {th }}$ day of cultivation on colloidal solutions of non-stabilized (Mn, $\mathrm{Cu})$ and stabilized $\left(\mathrm{Mn}^{+}, \mathrm{Cu}^{+}\right)$nanoparticles of essential metals and their oxides.

\section{Results}

\section{Growth response}

The obtained results testify that the colloidal solutions of stabilized and non-stabilized NPs of essential metals and their oxides do influence the growth of the roots of Allium cepa L. (Fig. 2). Morphometric indices of onion roots under the cultivation on experimental solutions are summarized in Table 2.

The solution of Mn NPs contributed to the roots growth by $52 \%$, and $\mathrm{Cu}$ NPs, on the contrary, caused stunting by $49 \%$ (Fig. 3).

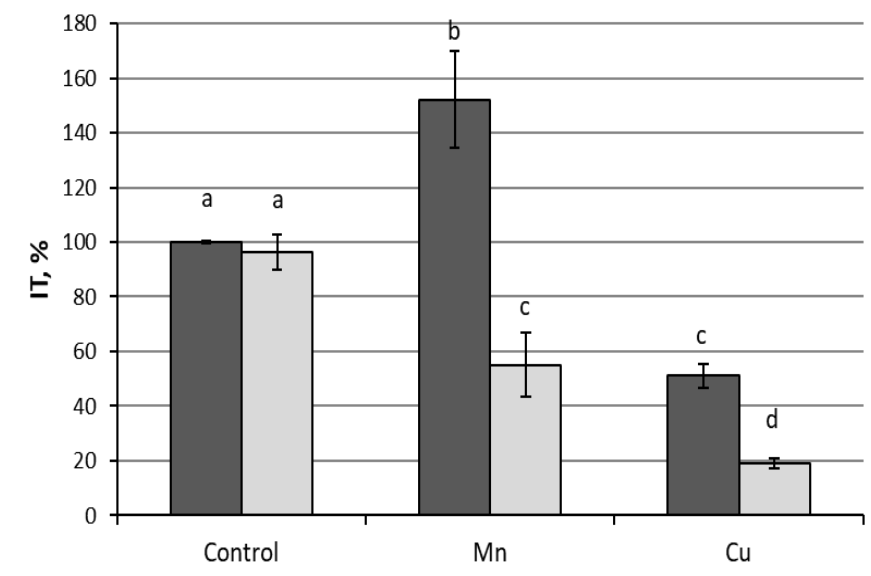

Fig. 3. Index of tolerance (IT, \%) of Allium cepa L., calculated by fresh weight of roots, on $5^{\text {th }}$ day of cultivation on colloidal solutions of non-stabilized (-citrate; black columns) and stabilized (+citrate; grey columns) nanoparticles of essential metals and their oxides. Data represent mean values with standard deviation of 3 replicates. Means followed by the same letters were not significantly different at $P<0.05$ according to the Duncan's multiple range test. 
Table 2. Morphometric parameters of Allium сера L. roots under cultivation on colloidal solutions of stabilized and nonstabilized nanoparticles of essential metals and their oxides.

\begin{tabular}{|c|c|c|c|c|}
\hline \multicolumn{2}{|c|}{ Experimental variant } & \multirow{2}{*}{$\begin{array}{c}\begin{array}{c}\text { Fresh weight of roots } \\
\text { per } \mathbf{1} \text { bulb [g] }\end{array} \\
0.09 \pm 0.03\end{array}$} & \multirow{2}{*}{$\frac{\text { Length }[\mathrm{mm}]}{19.55 \pm 2.42}$} & \multirow{2}{*}{$\frac{\text { Quantity of roots per } \mathbf{1} \text { bulb }}{12.63 \underline{+5.20}}$} \\
\hline & $\mathrm{H}_{2} \mathrm{O}$ distilled & & & \\
\hline Control & Trisodium citrate & $0.09 \pm 0.04$ & $19.90 \pm 3.63$ & $16.70 \pm 5.98$ \\
\hline \multirow{2}{*}{$\mathrm{Mn}$} & Non-stabilized & $0.13 \pm 0.04 *$ & $26.38 \pm 4.98 * *$ & $14.50 \pm 5.42$ \\
\hline & Stabilized & $0.02 \pm 0.02 * * *$ & $7.40 \pm 4.12 * * *$ & $6.00 \pm 3.33 * * *$ \\
\hline \multirow{2}{*}{$\mathrm{Cu}$} & Non-stabilized & $0.03 \pm 0.02 * * *$ & $5.00 \pm 1.25^{* * *}$ & $10.90 \pm 5.32$ \\
\hline & Stabilized & $0.006 \pm 0.004 * * *$ & $3.50 \pm 1.05^{* * *}$ & $2.51 \pm 0.83 * * *$ \\
\hline
\end{tabular}

Data represent mean values with standard deviation of 3 replicates.

Asterisks indicate the significance of difference at the level $* P \leq 0,05 ; * * P \leq 0,01 ; * * * P \leq 0,001$ according to Student's t-test.

The presence of the stabilizer in the colloidal solutions of NPs suppressed strongly the roots growth by 55 and $81 \%$ (according to the IT values) for $\mathrm{Mn}$ and $\mathrm{Cu}$ NPs, respectively. Besides, only the stabilized NPs limited the appearance of new roots in the experimental bulbs (Table 2). IT of plants grown on a solution of trisodium citrate did not differ significantly from the control values.

\section{Cyto- and genotoxicity}

To understand the causes of inhibition / stimulation of plant growth under the impact of NPs of essential metals, we conducted microscopic investigation of A. cepa $\mathrm{L}$. root meristem cells. Effect of colloidal solutions of stabilized and nonstabilized NPs on the root cells division is shown in Fig. 4. The cytotoxic effect was noted for all of the experimental solutions, except for the solutions

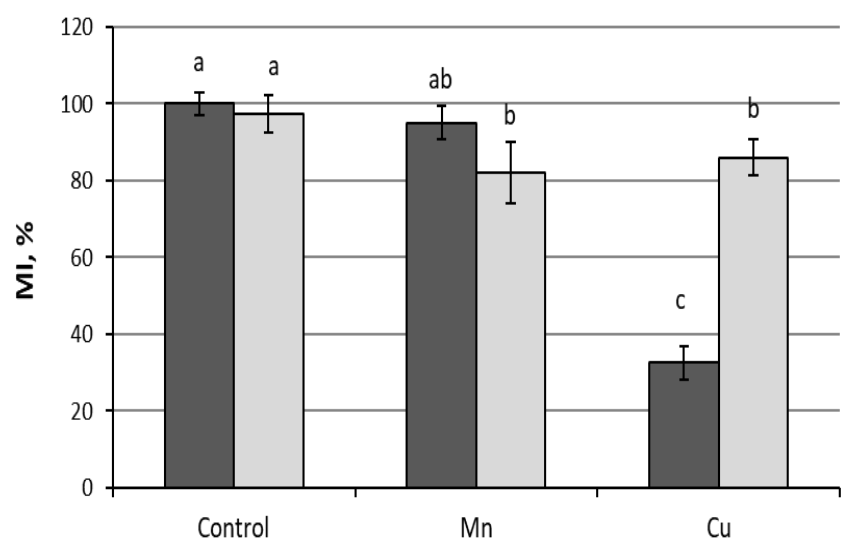

Fig. 4. Effect of colloidal solutions of non-stabilized (-citrate; black columns) and stabilized (+citrate; gray columns) nanoparticles of essential metals and their oxides on proliferative activity (MI, \%) of root meristem cells of Allium cepa L.. Data represent mean values with standard deviation of 5 replicates. of trisodium citrate and Mn NPs. In the latter case the MI of root meristem cells did not significantly differ from the control. The most reduced proliferative activity of cells of root apical meristem (by $68 \%$ ) was observed in plants grown on solutions of non-stabilized $\mathrm{Cu}$ NPs, that correlates with tolerance indices of the same experimental variant. Solutions of stabilized NPs of both metals equally inhibited the division of root cells, by 18 and $14 \%$ for $\mathrm{Mn}$ and $\mathrm{Cu}$ NPs, respectively.

Proportion of mitotic phases (mainly meta-, anaand telophases) in MI value changed in A. cepa root cells that were exposed to solutions of the nonstabilized $\mathrm{Cu}$ NPs as well as to stabilized $\mathrm{Cu}$ and Mn NPs (Fig. 5). Treatment with solutions of stabilized NPs caused accumulation of cells in telophases, that led to inhibition of divisions. Along with increasing number of cells in anaand telophases as result of treatment with nonstabilized $\mathrm{Cu}$ NPs, the number of cells in metaphase was reduced, that revealed crucial for proliferative activity of root meristem.

As shown in the representative microscopic images (Fig. 6), the majority of chromosome aberrations were recorded in anaphase for almost all experimental variants: breakes, bridges, vagrant chromosomes and spindle abnormalities. Disturbed metaphase, with unorganized chromosomes on the equatorial plate, also known as C-metaphase, was observed in the root cells treated with nonstabilized Mn NPs (Fig. 5 e, f, g). No aberrations were identified in the cells exposed to nonstabilized $\mathrm{Cu}$ NPs, probably due to the lowest number of divided cells (according to MI values). However, besides typical stages of mitosis we also 


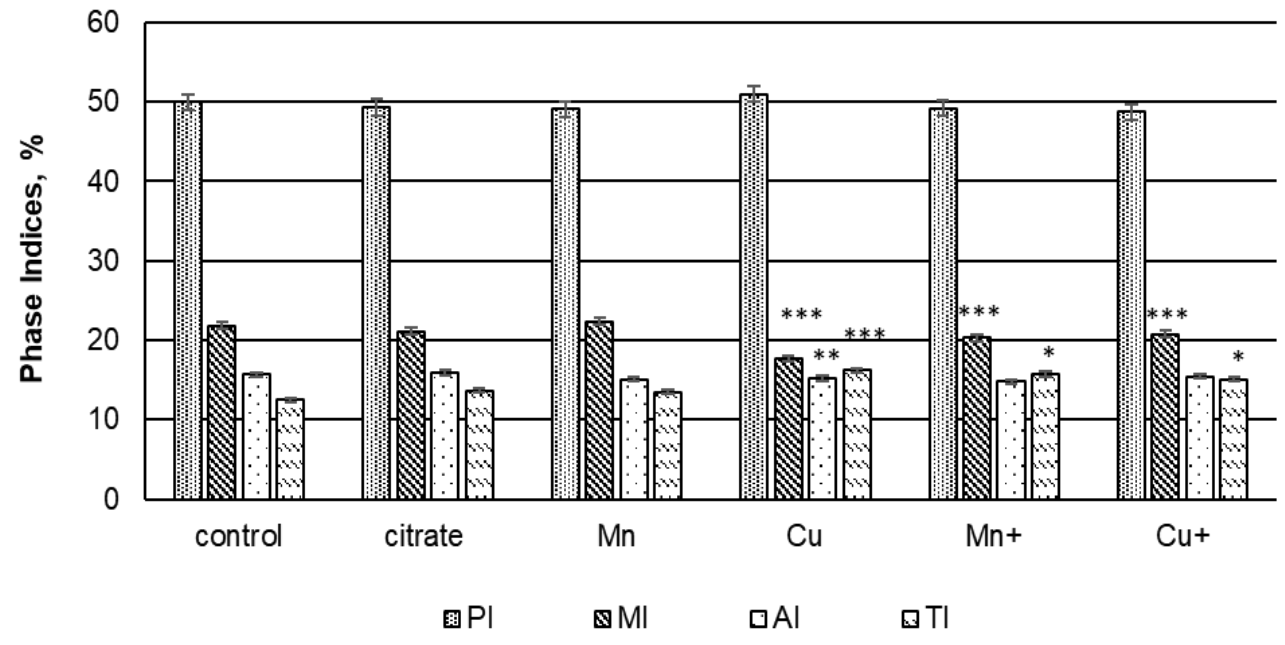

Fig. 5. Phase indices (\%) in Allium cepa L. root meristem cells exposed to colloidal solutions of non-stabilized $(\mathrm{Mn}$, $\mathrm{Cu})$ and stabilized $\left(\mathrm{Mn}^{+}, \mathrm{Cu}^{+}\right)$ nanoparticles of essential metals and their oxides. PI, MI, AI, TI pro-, meta-, ana- and telophase indices respectively. Data represent mean values with standard deviation of 5 replicates. Asterisks indicate the significance of difference at the level $* P \leq 0.05 ; * * P \leq 0.01$; $* * * P \leq 0.001$ according to Student's t-test. observed bridges in anaphase in the control root cells. Micronuclei were not detected in root cells in either of the experimental variants.

\section{Discussion}

The NPs of $\mathrm{Mn}$ and $\mathrm{Cu}$ for this study were chosen because these trace elements are essential for plants. They are components of active enzymes centres and participate in important processes such as photosynthesis, respiration etc. Recently, Mn NPs were suggested as an alternative to traditional fertilizers, since their revealed positive effect on the root and shoot growth and increased the productivity of crops. Moreover, they did not cause oxidative damages in plant tissues (Pradhan et al. 2013; Liu et al. 2016). Despite the fact that $\mathrm{Cu}$ NPs are part of many commercial antimicrobial formulations, their potential phytotoxicity is still being studied.

In the present research the onion root growth was dependent on the type of metal NPs in the culture medium, as has been shown previously (Konotop et al. 2014). Similarly to Liu et al. (2016) and Trujillo-Reyes et al. (2014), both $\mathrm{Cu}$ and $\mathrm{Mn}$ NPs showed inhibitory and stimulating effect on root growth, respectively. It has been shown that toxicity of $\mathrm{Cu}$ NPs and its oxides is connected to oxidative damage of root tissue in Arabidopsis, while the $\mathrm{Cu}$ NPs contributed much stronger to activation of oxidative stress-related genes than the corresponding $\mathrm{Cu}^{2+}$ ions (Tang et al. 2016). Since the mitotic activity of the root meristem was not affected by solutions of non-stabilized Mn NPs, enhanced root growth could be assumed with involving the compensatory mechanisms, namely intensive cell elongation (Table 2). On the other hand, mito-depressive effect was notable in plant cells treated with non-stabilized $\mathrm{Cu}$ NPs. According to PI values, smaller number of dividing cells in metaphase was detected along with abundant prophase stage cells, which is associated with the terminating of mitosis at the end of the prophase and delay in passing through the next cell division stages (Livanos et al. 2012). To less extent, such an effect was also observed in onion root cells treated with colloidal solutions of stabilized both $\mathrm{Mn}$ and $\mathrm{Cu}$ NPs.

Although separate cases of mitotic aberrations were recorded, we can not confirm the genotoxicity of studied NPs solutions in researched concentrations, because the frequency of observed chromosomal disturbances was at the control level. While the genotoxic effect has already been proven for some nano-sized materials including $\mathrm{Cu}$ NPs (Kumari et al. 2009; 2011; Pakrashi et al. 2014; Nagaonkar et al. 2015), there is scarce information concerning Mn NPs-induced genotoxicity.

The values of IT, MI and PI indicators of plants grown on the solution of trisodium citrate did not differ significantly from the control values. In light of this, the obtained data allow to speculate that stabilized NPs acquire novel properties or functional qualities compared to non-stabilized ones, as has been reported previously (Cunningham et al. 2013; Sharma et al. 2014). It could mainly be connected with altered phase composition of tested solutions, rather than with the size of metal particles. 

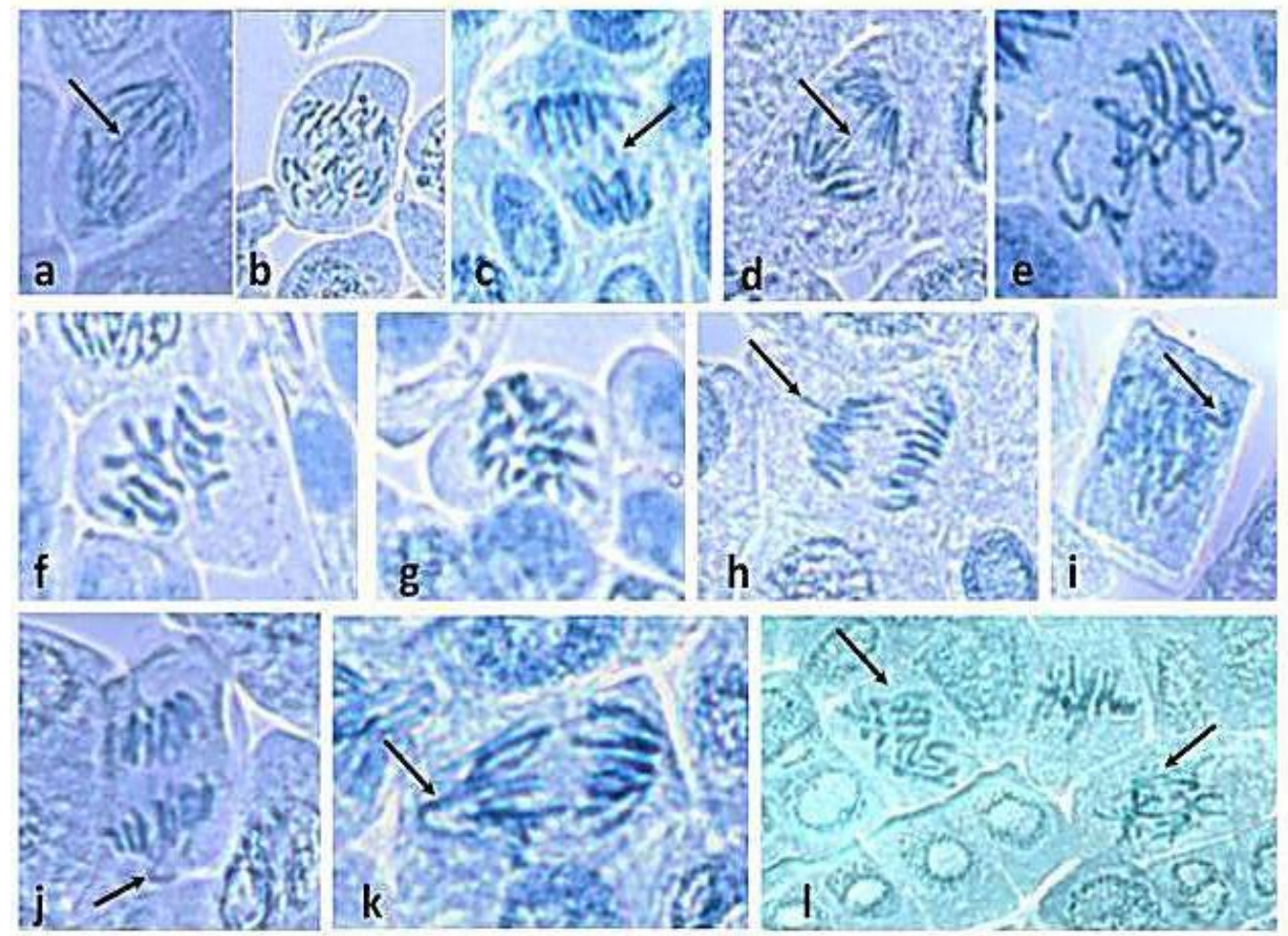

Fig. 6. Aberrations induced by colloidal solutions of nonstabilized and stabilized nano-particles of essential metals and their oxides in root meristem cells of Allium cepa L.: $\mathrm{a}$ - control, b - trisodium citrate, $\mathrm{c}-\mathrm{h}-$ non-stabilized Mn nanoparticles, i-k stabilized $\mathrm{Mn}$ nanoparticles, 1 - stabilized $\mathrm{Cu}$ nanoparticles. Types of observed aberrations: anaphase with bridge $(\mathrm{a}, \mathrm{d}, \mathrm{l})$; anaphase with breakes (c); spindle abnormalities in ana-phase (b, i, l); C-metaphase (e, f, g); vagrant chromosome in ana-phase (h, i, j, k). Magnification 400x.
Despite of unaffected mitotic activity of cells, there was a significant delay in root growth (IT) as likely consequence of the terminated root elongation. The cell expansion can be explained by the "acid growth theory", which postulates auxin-induced activation of plasma membrane-localized $\mathrm{H}^{+}$-ATPase that acidifies the apoplast (Rayle and Cleland 1992). Thus, an electrochemical gradient for absorbing $\mathrm{K}^{+}$is provided, which is necessary to increase the cell turgor and further strain. Recently, the auxin-dependent growth mechanism was also confirmed for root cells: high auxin concentrations suppressed, while low stimulated their elongation (Barbez et al. 2017). Moreover, it was reported that $\mathrm{CuO}$ NPs influenced the metabolism of cotton plants through hormonal imbalance, namely auxins (Van et al. 2016).

Owing to the greater correlation between surface area and mass compared to bulk metals, NPs have high reactivity, can form complexes with membrane transporters and, thus, be taken up by plant (Liu et al. 2016). In this way, stabilized NPs with different properties compared to non-stabilized, might directly or indirectly affect elongation of root cells, as well as the emergence of new root growth points.

\section{Conclusions}

The phytotoxicity of the colloidal solutions of essential metal NPs and their oxides obtained in the presence and absence of a stabilizer was tested and compared. The solutions of stabilized $\mathrm{Mn}$ and $\mathrm{Cu}$ NPs retarded the growth and development of Allium cepa L. roots, although the proliferative activity of root apical meristem remained unaffected and genotoxicity was not confirmed. In contrast, non-stabilised $\mathrm{Cu}$ NPs caused significant mito-depressive effect. It can be assumed that phytotoxicity of colloidal solutions of NPs of essential metals and their oxides depends on their properties, mainly phase composition altered by applied stabilizers; the mechanisms of their action on root growth, however, remains unclear. The wider implementation of nano-sized products in different human practices requires further research and careful control in regard of the impact on environment.

\section{Acknowledgement}

This work was supported by the President's of Ukraine grant for competitive projects of the State Fund for Fundamental Research (contract no. Ф75/170-2018 from 20.09.2018). We would like to thank Dr. M.V. Karpets from National 
Technical University of Ukraine "Igor Sikorsky Kyiv Polytechnic Institute" for the X-ray investigation of colloidal solutions of stabilized / non-stabilized $\mathrm{Cu}$ - and Mn-based NPs.

\section{Conflict of Interest}

The authors declare that they have no conflict of interest.

\section{References}

Abdel Latef AAH, Abu Alhmad MF, Abdelfattah KE (2017) The possible roles of priming with $\mathrm{ZnO}$ nanoparticles in mitigation of salinity stress in lupine (Lupinus termis) plants. J. Plant Growth Regul. 36: 60-70.

Auffan M, Rose J, Bottero JY, Lowry GV, Jolive JP, Wiesner MR (2009) Towards a definition of inorganic nanoparticles from an environmental, health and safety perspective. Nat. Nanotechnol. 4: 634-641.

Barbez E, Dünser K, Gaidora A, Lendl T, Busch W (2017) Apoplastic $\mathrm{pH}$ regulation in A. thaliana roots. Proc. Natl. Acad. Sci. USA. 114: E4884-E4893.

Cunningham S, Brennan-Fournet ME, Ledwith D, Byrnes L, Joshi L (2013) Effect of nanoparticle stabilization and physicochemical properties on exposure outcome: acute toxicity of silver nanoparticle preparations in zebrafish (Danio rerio). Environ. Sci. Technol. 47: 3883-3892.

Dimkpa CO, Calder A, Britt DW, McLean JE, Anderson AJ (2011) Responses of a soil bacterium, Pseudomonas chlororaphis $\mathrm{O6}$ to commercial metal oxide nanoparticles compared with responses to metal ions. Environ. Pollut. 159: 1749-1756.

Ditta A, Arshad M (2016) Applications and perspectives of using nanomaterials for sustainable plant nutrition. Nanotechnol. Rev. 5: 209-229.

Fiskesjo G (1997) Allium-test for screening chemicals; evaluation of cytologic parameters. In Wang W, Gorsuch JW, Hughes JS (Eds.) Plants for environmental studies, Boca Raton, CRC Lewis Publishers, New York, p. 308.

Fiskesjo G (1985) The Allium-test as a standard in environmental monitoring. Hereditas. 10: 99-112.

Fu PP, Xia Q, Hwang H-M, Ray PC, Yu H (2014) Mechanisms of nanotoxicity: Generation of reactive oxygen species. J. Food Drug Anal. 22: 64-75.

Gottschalk F, Sun T, Nowak B (2013) Environmental concentrations of engineered nanomaterials: review of modeling and analytical studies. Environ. Pollut. 181: 287-300.

Griffitt RJ, Luo J, Gao J, Bonzongo J, Barber DS (2008) Effects of particle composition and species on toxicity of metallic nanomaterials in aquatic organisms. Environ. Toxicol. Chem. 27: 1972-1978.

Horie M, Fujita K, Kato H, Endoh S, Nishio K, Komaba LK, Nakamura A, Miyauchi A, Kinugasa H, Hagihara Y, Niki E, Yoshida Y, Iwahashi H (2012) Association of the physical and chemical properties and the cytotoxicity of metal oxide nanoparticles: metal ion release, adsorption ability and specific surface area. Metallomics. 4: 350-360.

Konate A, He X, Zhang Z, Ma Y, Zhang P, Alugongo GM, Rui Y (2017) Magnetic $\left(\mathrm{Fe}_{3} \mathrm{O}_{4}\right)$ nanoparticles reduce heavy metals uptake and mitigate their toxicity in wheat seedling. Sustainability 9: 790 .

Konotop YeO, Kovalenko MS, Ulynets VZ, Meleshko AO, Batsmanova LM, Taran NYu (2014) Phytotoxicity of colloidal solutions of metal-containing nanoparticles. Cytol. Genet. 48: 99-102.

Kumari M, Mukherjee A, Chandrasekaran N (2009) Genotoxicity of silver nanoparticles in Allium cepa. Sci. Total Environ. 407: 5243-5246.

Kumari M, Khan SS, Pakrashi S, Mukherjee A, Chandrasekaran N (2011) Cytogenetic and genotoxic effects of zinc oxide nanoparticles on root cells of Allium cepa. J. Hazard. Mater. 190: 613621.

Lee S, Kim S, Lee I (2012) Effects of soil-plant interactive system on response to exposure to $\mathrm{ZnO}$ nanoparticles. J. Microbiol. Biotechnol. 22: 1264-1270.

Lin SY, Tsai YT, Chen C-C, Lin CM, Chen C-H (2004) Twostep functionalization of neutral and positively charged thiols onto citrate-stabilized $\mathrm{Au}$ nanoparticles. J. Phys. Chem. B. 108: 2134-2139.

Livanos P, Apostolakos P, Galatis B (2012) Plant cell division: ROS homeostasis is required. Plant Signal. Behav. 7: 771-778.

Liu RQ, Zhang HY, Lal R (2016) Effects of stabilized nanoparticles of copper, zinc, manganese, and iron oxides in low concentrations on lettuce (Lactuca sativa) seed germination: nanotoxicants or nanonutrients? Water Air Soil Pollut. 227: 1-14.

Lopatko KG UA Patent 38459, 2009.

Ma H, Williams PL, Diamond SA (2013) Ecotoxicity of manufactured $\mathrm{ZnO}$ nanoparticles - a review. Environ. Pollut. 172: 76-85.

Mirzajani F, Askari H, Hamzelou S, Farzaneh M, Ghassempour A (2013) Effect of silver nanoparticles on Oryza sativa L. and its rhizosphere bacteria. Ecotox. Environ. Safe. 88: 48-54.

Nagaonkar D, Shende S, Rai M (2015) Biosynthesis of copper nanoparticles and its effect on actively dividing cells of mitosis in Allium cepa. Biotechnol. Prog. 31: 557-565.

Navarro E, Baun A, Behra R, Hartmann NB, Filser J, Miao AJ, Quigg A, Santschi PH, Sigg L (2008) Environmental behavior and ecotoxicity of engineered nanoparticles to algae, plants, and fungi. Ecotoxicology 17: 372-386.

Olkhovych O, Svietlova N, Konotop Y, Karaushu O, Hrechishkina S (2016) Removal of metal nanoparticles colloidal solutions by water plants. Nanoscale Res. Lett. 11: 518

Pakrashi S, Jain N, Dalai S, Jayakumar J, Chandrasekaran PT, Raichur AM (2014) In vivo genotoxicity assessment of titanium dioxide nanoparticles by Allium cepa root tip assay at high exposure concentrations. PLoS One. 9: 877-889. 
Pradhan S, Patra P, Das S, Chandra S, Mitra S, Dey KK, Akbar S, Palit P, Goswami A (2013) Photochemical modulation of biosafe manganese nanoparticles on Vigna radiata: a detailed molecular, biochemical, and biophysical study. Environ. Sci. Technol. 47: 13122-13131.

Rayle DL, Cleland RE (1992) The acid growth theory of auxin-induced cell elongation is alive and well. Plant Physiol. 99: 1271-1274.

Rui MM, Ma CX, Hao Y, Guo J, Rui YK, Tang XL, Zhao Q, Fan X, Zhang ZT, Hou TQ, Zhu SY (2016) Iron oxide nanoparticles as a potential iron fertilizer for peanut (Arachis hypogaea). Front. Plant Sci. 7: 815.

Ruttkay-Nedecky B, Krystofova O, Nejdl L, Adam V (2017) Nanoparticles based on essential metals and their phytotoxicity. J. Nanobiotechnology 15: 33.

Saxena R, Tomar RS, Kumar M (2016) Exploring nanobiotechnology to mitigate abiotic stress in crop plants. J. Pharm. Sci. Res. 8: 974-980.

Scrinis G, Lyons K (2007) The emerging nano-corporate paradigm: nanotechnology and the transformation of nature, food and agri-food systems. Int. J. Sociol. Food Agric. 15: 22-44.

Sharma VK, Siskova KM, Zboril R, Gardea-Torresdey JL (2014) Organic-coated silver nanoparticles in biological and environmental conditions: fate, stability and toxicity. Adv. Colloid Interface Sci. 204: 15-34.

Sperling RA, Parak WJ (2010) Surface modification, functionalization and bioconjugation of colloidal inorganic nanoparticles. Phil. Trans. R. Soc. A. 368: 1333-1383.

Tang Y, He R, Zhao J, Nie G, Xu L, Xing B (2016) Oxidative stress-induced toxicity of $\mathrm{CuO}$ nanoparticles and related toxicogenomic responses in Arabidopsis thaliana. Environ. Pollut. 212: 605-614.

Taran N, Batsmanova L, Kovalenko M, Okanenko A (2016) Impact of metal nanoform colloidal solution on the adaptive potential of plants. Nanoscale Res. Lett. 11: 89 .

Teplicky T, Chorvat D, Michalka M, Marcek Chorvatova A (2018) Preparation of metal nanoparticles by femtosecond laser ablation. Nova Biotechnol. Chim. 17: 38-47.

Trujillo-Reyes J, Majumdar S, Botez CE, Peralta-Videa JR, Gardea-Torresdey JL (2014) Exposure studies of coreshell $\mathrm{Fe} / \mathrm{Fe}_{3} \mathrm{O}_{4}$ and $\mathrm{Cu} / \mathrm{CuO}$ NPs to lettuce (Lactuca sativa) plants: are they a potential physiological and nutritional hazard? J. Hazard. Mater. 267: 255-263.

Van NL, Ma C, Shang J, Rui Y, Liu S, Xing B (2016) Effects of $\mathrm{CuO}$ nanoparticles on insecticidal activity and phytotoxicity in conventional and transgenic cotton. Chemosphere. 144: 661-670.

Wilkins DA (1978) The measurement of tolerance to edaphic factors by means of root length. New Phytol. 80: 623633. 